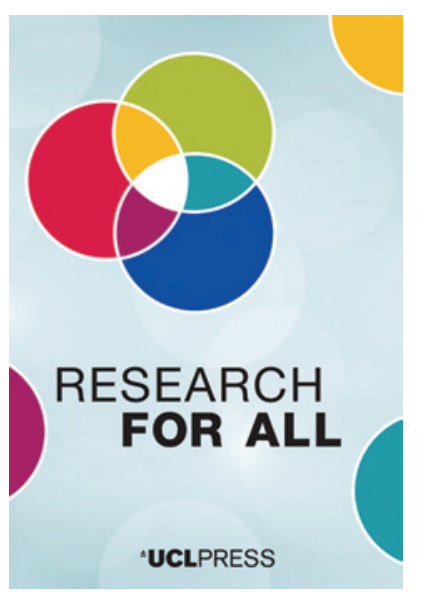

${ }^{ \pm}$UCLPRESS

\title{
RESEARCH FOR ALL
}

The open-access journal for public engagement with research

ISSN 2399-8121 (Online)

Journal homepage:

https://www.uclpress.co.uk/pages/research-for-all

\section{Mind the gap: Can a professional development programme build a university's public engagement community?}

Amy Seakins (iD and Alexandra Fitzsimmons (iD

\section{How to cite this article}

Seakins, A. and Fitzsimmons, A. (2020) 'Mind the gap: Can a professional development programme build a university's public engagement community?' Research for All, 4 (2), 291-309. Online. https://doi.org/10.14324/RFA.04.2.11

Submission date: 10 May 2019

Acceptance date: 10 February 2020

Publication date: 22 September 2020

\section{Peer review}

This article has been peer-reviewed through the journal's standard double-blind peer review, where both the reviewers and authors are anonymized during review.

\section{Copyright}

(C) 2020 Seakins and Fitzsimmons. This is an open-access article distributed under the terms of the Creative Commons Attribution Licence (CC BY) 4.0 https://creativecommons.org/licenses/ by/4.0/, which permits unrestricted use, distribution and reproduction in any medium, provided the original author and source are credited.

\section{Open access}

Research for All is a peer-reviewed open-access journal. 


\title{
Mind the gap: Can a professional development programme build a university's public engagement community?
}

\author{
Amy Seakins* and Alexandra Fitzsimmons - Imperial College London, UK
}

\begin{abstract}
A number of 'gaps' may be present within public engagement with research disparity of skills, priorities and knowledge between research staff and engagement practitioners, as well as differences between institutional ambition and departmental reality. Such gaps are often perceived as problems - deficits to be addressed through training and culture change initiatives. The design and delivery of Imperial College London's Engagement Academy with 12 members of research, teaching and professional services staff sought to explore and work across such gaps. We propose that these areas of disconnect within and across universities may be challenging, but they may also be structurally necessary, and potentially even a source of rich public engagement.
\end{abstract}

Keywords: training, capacity building, skills development, engagement culture, engagement with research, university

\section{Key messages}

- Diverse roles are involved in public engagement within universities, including those working in research, academia and professional services, at institutional and departmental levels. This diversity is necessary within a large organization, and working with areas of disconnect rather than trying to eliminate them is key to supporting public engagement.

- In this context of diversity, reflection and building confidence are pivotal to supporting individuals in a range of roles to develop agency and identity in public engagement. This enables individuals to work across research and engagement cultures, and to support others to do so.

- Reflection skills, confidence and a sense of agency can all be supported through a long-term training initiative that focuses as much or more on building community as on imparting knowledge. For us, this was a seven-day Engagement Academy across seven months, supporting the development of a community of engagement practitioners through workshops, seminars, presentations, discussions and peer support.

\section{Public engagement progress and practice in universities}

Amid supportive movements in policy and funding, higher education institutions are making headway in embedding public engagement alongside other core agendas of research and teaching. Institutional funding has been awarded to a number of universities to drive culture change around engaged research, leading to the growth 
of engagement teams and infrastructure (NCCPE, n.d.; NCCPE and RCUK, 2017). Research points to a 'major shift or "sea change" in professional scientific culture toward an endorsement of, and participation in, public engagement as a key component of scientific research and innovation' (Burchell et al., 2009: 6). Engagement now features in the strategic missions of many higher education institutions and is led by senior champions; in 2015 over 85 per cent of UK universities had in place a senior leader with responsibility for public engagement (Owen et al., 2016). So, sector wide, it seems there is much to toast in the year that the National Co-ordinating Centre for Public Engagement (NCCPE) celebrates its tenth birthday.

But although the landscape for public engagement with research has been developing in a positive direction, there may be more to do within institutions themselves. While more researchers feel that public engagement is important to their role, the level of participation in public engagement varies and shows a much slower growth (Hamlyn et al., 2015). Within these large and diverse institutions, there are two areas of disconnect that may present challenges for engaged research - these can be considered as structural and cultural, and they are introduced below. It is within this context that a team at Imperial College London developed a new internal engagement initiative, the Engagement Academy, to better understand and respond to these gaps and support further public engagement.

\section{The researcher-institution 'gap'}

Previous studies have identified a structural 'gap' between researchers and their institutional strategies or programmes. Public engagement may be incorporated in the majority of university missions, and institutional initiatives such as awards provide toplevel support for engagement, but how this is locally translated and embedded within departments and the work of individual researchers can be problematic. Owen et al. (2016: 30) write: 'we continue to see a mismatch between the steps that universities and funders have taken to embed public engagement and how these are actually experienced by researchers'. Possible causes may be the level of support, recognition, infrastructure and resource available:

The disconnect between researchers and institutions is manifest in a number of ways in the data. For instance, although ... well over half of researchers indicated that they feel that encouragement from their institution for public engagement has increased over the past ten years, the corresponding figure for practical support (such as training) is well under half. (Burchell et al., 2017: 218)

University staff must navigate barriers to get involved in public engagement. Survey respondents stated that competing pressures on their time were among the main factors preventing them from getting involved in further public engagement (61 per cent, Hamlyn et al., 2015). Other key structural barriers included a perceived lack of opportunities or difficulty finding relevant audiences (26 per cent); lack of funding (26 per cent); and a perceived lack of recognition of the value of public engagement by others (18 per cent). For some, public engagement is not only not rewarded at the institutional level, but it is also perceived to be met with 'apathy, ambivalence and hostility' (Watermeyer, 2015: 336).

These barriers translate into a tension for researchers specifically (rather than for higher education staff more generally) in terms of career progression. From interviews with 40 UK academics active in public engagement, Watermeyer (ibid.: 334) presents a negative picture: 
Respondents' accounts, for the most part, coalesced around a narrative of PE-HE [public engagement in higher education] as inhibitive and deleterious to research identities and careers. Respondents spoke of a lack of institutional interest, acknowledgement, incentivisation and reward for PE-HE, that their association with PE-HE had diluted and despoiled their reputation as researchers; and had caused distancing from research activity where principal investigators and research managers exploited their PE status as an opportunity to off-load administrative chores.

While it seems, therefore, that we have come a long way in terms of growing a culture of engagement within and across our institutions, all is not complete and the situation has been described as a 'work in progress' (Burchell et al., 2017).

\section{Cultural differences}

An important part of the university public engagement dynamic could be understood as cultural, rather than structural. As indicated in the first editorial of Research for All, public engagement with research includes 'a range of different communities, with different cultures and languages', both within and outside our institutions (Duncan and Oliver, 2017: 3). Chilvers (2013) identifies many different actors involved in orchestrating, practising, studying and coordinating public dialogue around science including engagement practitioners, social science academics, scientists and scientific institutions, government, industry and institutions such as the NCCPE. These actors often shift, and wear many hats, meaning that the landscape is complex and diverse.

Key areas of disconnect observed include between those researching social science, STEM (science, technology, engineering and mathematics) researchers, and the engagement practitioners themselves. While there may be similarities (such as the pressure to publish, attend conferences and win grants), these groups can be considered often to inhabit different cultural worlds, perhaps for many years. Salmon et al. (2017) explore the linguistic and conceptual differences of these contrasting cultural worlds through a reflective account of an encounter between a scientist, a social scientist and a science writer. They suggest that what is needed is further reflexive practice to become aware of the cultural differences, along with the co-production of knowledge about engagement between these groups.

One of the differences identified between the three different cultures represented in Salmon's (ibid.) paper was about aims and intentions for public engagement. Almost three-quarters of UK researchers feel that they have a moral responsibility to engage with the public as part of their role in research and higher education (73 per cent, Hamlyn et al., 2015). Yet, Salmon et al. (2017: 54) describe that there is:

a stark difference between the assumption by many scientists that the goal of communication is to raise awareness, transmit the importance of science or correct misconceptions, and the assumption in much of the PES [public engagement with science] literature that the goal of engagement should be to enable democratic publics to influence decisions about the development and use of science and technology.

Similarly, language and definitions of public engagement differ between groups. While many institutions and engagement practitioners might use the term 'public engagement' to mean a two-way interaction to share knowledge and experiences for mutual benefit, researchers may be more likely to describe a mixed or one-way or 'deficit' model of communication where knowledge is transmitted from one party 
to another (Besley and Tanner, 2011; Grand et al., 2015). Scientists had similar views with regard to engagement training - valuing training and considering it to be most appropriate when it focused on making messages understandable and explaining scientific phenomena to the public (Besley et al., 2015).

Duncan and Oliver (2017: 3) discuss the issue of terminology: 'no one language can capture the full breadth and depth of engagement across the landscape, as terms that seem similar on the surface can refer to quite diverse practices'. Language can present a challenge, not only when defining what public engagement is, but also in interactions more broadly between these different cultures:

Words or phrases experienced as obfuscating [by the science writer] included: scientism and scientistic, governance (as in governance of science), political imaginaries, deliberative democracy, and normative. Lack of familiarity with these terms also sometimes led to misinterpretation, which in turn resulted in serious misunderstandings ... While the social scientist has herself been exasperated by the proliferation of jargon in social-science studies of science, these terms would not have been classified as such by her. (Salmon et al., 2017: 56)

While studies have identified the influence of structural factors in the participation of researchers in public engagement, Poliakoff and Webb (2007) found that, along with prior experience in engagement, three cultural factors had most influence when surveying scientists about predicted public engagement behaviours over the next year: attitude to public engagement and its benefits; having the confidence, capability and skills to participate; and whether researchers believed their colleagues participated in public engagement. Together these cultural factors may provide the intention to participate in engagement, and removing the structural barriers described above may enable intentions to be translated into actual behaviours (ibid.).

\section{Training initiatives in the context of structural and cultural 'gaps'}

Despite the challenges discussed above, cultural variances are necessary and valuable. They are not unique to public engagement, and they are prevalent across higher education institutions and many other sectors. The different cultures described above are each specialisms, and as such they are rich in appropriate, necessary expertise. Different parts of a university will, equally and rightly, have different agendas. Therefore, these gaps became important considerations in thinking about how a training programme could support individuals across the institution to develop their public engagement capacity.

Besley et al. (2018) found that the strongest predictors of researchers' willingness to get involved in engagement were positive attitudes towards the experience, such as believing that they were likely to enjoy the experience, they were likely to make a difference through engagement, and feeling as though they have the time to engage. Relatedly, when researchers were asked what would encourage them to get more involved in public engagement, just under half (48 per cent, Hamlyn et al., 2015) said that they would be encouraged if they were relieved of other work. An invitation to take part would encourage 38 per cent to take part, and training would encourage just over a fifth (21 per cent) (ibid.). When surveyed, science communication experts also felt that the science research community could benefit from further training in public engagement and communication (Besley and Tanner, 2011).

The national picture shows low uptake in terms of public engagement training; just under three in ten researchers (28 per cent) had received formal training in either 
communications or public engagement in the previous five years, and learning through experience or from peers was much more common (Burchell et al., 2017). When received, training was largely focused on media, public speaking and social media. While many other public engagement training courses have focused on developing understanding and skills, fewer aim to support the development of identities as engagement practitioners, and of reflective practice (Baram-Tsabari and Lewenstein, 2017).

In this context, rather than attempting to 'fix' the gap with knowledge and skills development, our vision for a training programme became about supporting individuals to have the agency to collaborate across, round and through the gap: it became about developing confidence, building community, understanding each other, and networking. We decided early on that participants' projects and identities were to be at the heart of all teaching. Our approach mirrors recommendations from the wider continuing professional development literature in two key areas. The first is based on social learning theories that build communities of practice where individuals are able to construct meanings, knowledge and identities through social participation (Wenger, 1998). The second is about the importance of reflective practice in evaluating past or current behaviours with the intention to learn for future actions (Schon, 1983).

\section{The local context at Imperial College London and the introduction of the Engagement Academy}

This paper reflects on a training initiative at Imperial College London, the Engagement Academy. Imperial is a research-intensive institution, with specialisms in science, engineering, medicine and business. Around eight thousand members of staff work at Imperial across nine campuses and hospitals and four research faculties. Societal Engagement is an integral part of the current College Strategy, and is supported by a central team and initiatives. The Engagement Academy is one part of a broader programme of capacity-building activities, including a suite of short masterclasses, sessions for graduate students, seed funding, networks, and an awards scheme for societal engagement that sits alongside those for research and education.

As well as potential benefits to those attending the training, it also seemed that a training programme could be an important way for us to listen to our own community - those on the other side of the 'department-institution gap'. Our relationships with those working in research teams was often distant: one-off encounters at events, or occasional meetings to explore specific questions. It was also skewed. Those we encountered more often were likely to be those most confident in delivering public engagement activities - they were engagement professionals embedded in departments, or academics with established histories of public engagement activity. We knew much less about the day-to-day reality of those at earlier stages of building a practice in the area.

At the time of writing, the Academy has seen two cohorts, but this paper focuses on the first year's work. The authors of this paper led, with the support of colleagues, the development and delivery of the programme. Amy Seakins is Imperial College's Engagement Manager (Capacity Building and Evaluation) and holds a PhD in Public Engagement with Science, while Alexandra Fitzsimmons teaches on the university's MSc Science Communication programme and is also a founder of a maths-based family learning charity. In terms of the 'gaps' above, both are engagement practitioners, with academic social science credentials, and the programme was a central, institutional initiative. 


\section{The approach: What is an Engagement Academy?}

Reflection on identity and practice, and the creation of a community, are not goals that can be achieved in a short period of time. After much discussion, including with potential delegates, Imperial committed to a programme of seven days of teaching spread over seven months. The response from staff showed similar commitment. Twelve members of staff completed the first Academy, including researchers, teaching fellows and professional services staff (centre managers, research technicians and coordinators) from a range of departments across the university.

The Academy had three phases, which together were designed to support participants to get to know each other, collaborate, and reflect on identity and practice:

- Sessions 1-3, Portrait, Map, Mantra, were a reflection on the relationship between science and society. This included reading academic social science papers, a visit to the National Army Museum, London to experience being an 'outsider' to a topic, and a panel session about Imperial's aims for public engagement.

- Sessions 4-6, Initiate, Craft, Evaluate, were an exploration of practice, with guest speakers on topics such as evaluation, and plenty of time for delegates to workshop their own ideas.

- Session 7, Reflection and Celebration, was a final session to link together the thinking, and to celebrate what our delegates had achieved.

All sessions were heavily discussion-based with a lot of small group work. Within each day, we aimed for a repeating structure: time to catch up with each other's projects at the start; a seminar-type discussion session exploring the day's theme; a presentation-type session with an external expert or panel discussion, for example on science in the media or engagement opportunities at Imperial; and a practical session, whether in podcasting, writing or exhibit creation. There was an hour's lunch break, with lunch provided, and we always concluded with reflection and evaluation.

The structure draws on best practice within STEM communications skills training by including interactive sessions and discussions, emphasizing learning by doing and practical experience, and facilitating reflection (Silva and Bultitude, 2009). Training developed by the European Science Communication Network involved a similar mix of practical skills development sessions and discursive sessions on wider issues of science and society (Miller et al., 2009). Our iteration at Imperial included the added factor of these sessions taking place over an extended period of time alongside the development of participants' own projects.

The methodology and content were drawn in part from the Science Communication Unit's 25-year-old MSc in science communication (Mellor, 2013). This popular MSc mixes academic and practical teaching, and has community building at its heart, with numbers managed to ensure that students can build relationships. We drew on the MSc to think about how to build community, about how academic and practical teaching relate, and about pedagogy that prioritizes drawing out of knowledge rather than dissemination of facts.

Another influence was the methodology of the School for Social Entrepreneurs (SSE), of which one of the authors (AF) is a fellow. The SSE's fellowship course is a nine-month learning experience with around three days' contact time per month more intense than the Academy, but with the same principle of occasional contact time with plenty of space to respond to, reflect on and act on the teaching in between. The SSE prizes interactions between students over teacher-student interactions, and it draws heavily on social entrepreneur role models to share their experiences. 
Its relevance to the Academy is to do with the type of skills our delegates needed: particularly, the entrepreneur's sense of their own agency.

We were careful to be transparent with our delegates about the newness of the Academy, and we aimed to model what we felt were good engagement values. For example, our repeated evaluation sessions had different formats each time, so that we had plenty of varied opportunity to hear from delegates, and so that they could experience a range of feedback methods.

\section{Evaluating and reflecting on the Academy}

Our evaluation of the Academy aimed to answer the key research question: Is an 'Engagement Academy' professional development programme an effective way to support university staff to develop their public engagement practice? Evaluation focused on two areas: the effectiveness of the session format and content, and the potential impacts on the individuals taking part. Feedback from the 12 participants in the first Engagement Academy cohort forms the data for this paper, alongside the observations and reflections of the authors. All names have been anonymized using pseudonyms selected by participants.

Both of the authors were involved in the development and delivery of the Academy, meaning that we were active participants in the discussions and activities, and our own observations and reflections fed into our actions and evaluation. The approach followed key features of ethnography, which include research taking place over an extended period of time, researchers being immersed within the research environment themselves (often playing key roles), and use of observation and qualitative in-depth feedback (Savin-Baden and Howell Major, 2013). Methods included:

1) Interviews. The main research method was individual interviews, conducted with 9 of the 12 individuals between four and five months following the completion of the course. The 3 individuals who did not participate in the interviews reported a lack of time and availability. Interviews were semi-structured, and followed a schedule of question prompts including: any engagement activity the participant had been involved with since the end of the Academy; what had stuck with them most from the course; their reflections on the impacts (if any) that the Academy had on their engagement work, everyday role/research, personal skills and attitudes, and impacts on their colleagues. Interviews were conducted face-to-face, audio-recorded and later transcribed, and lasted between 16 and 45 minutes.

2) Group discussion. As part of the final session, the group participated in a semistructured discussion to reflect on the course as a whole. Questions were posed about the impacts of the course and participation in any engagement activities on their engagement practice, their work or research, their own attitudes and those of their colleagues. Feedback was also gathered on the course overall including the balance in formats, particularly well-received sessions or areas where improvements could be made.

3) Evaluation during the course. Feedback was collated during the Engagement Academy sessions via a range of evaluation techniques. Methods varied between sessions, and were focused on exploring the impacts of the session on aspects of the participants' public engagement practice, as well as on evaluating the approach for future programmes. Methods included written feedback (in person and online), voting, peer interviewing, group discussion and illustrated feedback. 
4) Reflections and observations. Due to the participatory nature of the evaluation, our own reflections and observations have fed into this paper. We used our experiences developing, delivering and participating in the course to add to the conclusions, inform the way we approached the evaluation and make tweaks and improvements to the programme.

Data were analysed thematically, involving identifying emerging themes or patterns and then refining using a constant comparative approach (Glaser and Strauss, 1967; Gibbs, 2007). Where similar topics or sentiments were mentioned multiple times, they were then coded to reflect the key content. Occurrences and patterns in the appearance of themes were also noted. Two participants from the Engagement Academy reviewed a draft paper to provide feedback on our interpretation of meaning and presentation. The interview transcripts, being such a rich data source, make up the main steer for the narrative below, with the findings and reflections from the other three methods supplementing and strengthening the conclusions reached.

\section{Findings: Did the Academy support participants - and how?}

Below, we explore how the structural and cultural disconnects discussed in the introduction affected, and were negotiated by, participants and the programme.

\section{Building community: Connecting a diverse cohort}

A diverse community of staff took part in the Academy. Participants were from a range of roles and departments across the university. We made a decision not to restrict the course to only academic or professional services staff, or to a particular faculty, but our selection of participants took into account a range of roles, levels of seniority, subjects and backgrounds. While two senior members of academic staff applied to the Academy, they were later unable to take part due to other commitments, and therefore the absence of senior academic staff in our cohort is a limitation in our study. The breakdown of participants across three faculties was six from Engineering, four from Medicine and two from Life Sciences. Participants were motivated by a range of potential outcomes of their own engagement. For example, participants hoped to break down misconceptions or stereotypical images of science and scientists, raise awareness of non-traditional science areas, and combat some of the issues around gender differences in science participation.

The development of community was a key feature in the design of our programme, and interviewees valued the network of which they had become part:

I think the community and the network [was key]. I think that is very important as well - the support of your peers. A sort of audience that you know they understand you and you can share your ideas. Although from the outset we were completely different people, but then somehow it worked. (Abby - professional services manager)

Participants were inspired by working with others from outside their immediate area:

Just how much fun it is to work with people outside of your working environment. Just with the people I was on the course with, and in general the public. Yeah, it is definitely hard work, but it is nice at the same time. (Sabina - professional services manager) 
Two participants specifically mentioned the importance of this diversity of perspectives:

I think what was nice about the programme in particular was that it did encourage that crossing between academic staff and administration, in particular, to get involved in public engagement activities. The idea is not 'oh you're in this type of role so you are only able to do certain things'. It actively discourages that ... Because it gives people the confidence, they can add a feather to their cap. And then you do get different ideas, people come up with different activities, apply different perspectives. People come up with their own different contribution to the engagement portfolio. (Christina - professional services senior manager)

Participants talked about how they had gained ideas and inspiration from others on the course through participating in activities together:

Seeing how other people try to go through the process, the materials they were producing was much more bespoke, they were looking at it through the eyes of the audience they were trying to engage. I don't think I was quite joining up those dots. (Christina - professional services senior manager)

There were a lot of people that were so inspiring. For example, Terry - let's go, public engagement, let's do this! So that really makes you change your perspective. (Maria - early career researcher)

Each session reiterated the importance of being reflective and evaluating ideas. Group members received feedback on their own engagement ideas, and discussions prompted them to review ideas raised by the museum visit, academic papers and invited speakers. This too was valued:

I mean, the big things I will miss is the space where we could discuss lots of things, lots of ideas and use each other as a sounding board for that. And get the additional perspectives. From things like going to a gallery as a group and having a discussion about how those things fit into other areas. That will be a big loss. And I enjoyed those days because I didn't have any restrictions on how to think and how to respond and what to then proceed. (Terry - early career researcher)

Supporting reflection within training has been shown to be key in encouraging participants to embed their new learning, and to take ownership over their development in engagement (Silva and Bultitude, 2009).

The fact that participants valued diversity among their fellow cohort, and felt that they learnt from one another, was important given the gaps discussed above - the cultural and structural differences added a richness to the network. The teaching style of the Academy - the discussion-based format, the long lunch break and the extended time frame - encouraged the participants to feel that the Academy was a 'safe space' in which to reflect and share ideas.

This dedicated space also encouraged people to consider new perspectives and ways of working, supporting them to expand beyond their everyday role, and hence work across some of the structural and cultural gaps:

For me, what I liked about it was that it [the Academy] encouraged people to step out of their immediate role and do it together on an equal basis. More programmes need to be like that. (Christina - professional services senior manager) 


\section{Learning about the structural 'gap' between institution and department}

Our reflections during the first Academy teaching period returned often to the subject of our own growing understanding: we were adding colour to our picture of life within research departments, and we were sometimes surprised by the magnitude of our own misapprehensions. This learning, which was substantiated by reflections from participants in follow-up interviews, falls into three themes: participants' view of the 'centre', career and time pressures, and diversity in roles and agency.

\section{View of the 'centre': Accessing institutional support for public engagement}

I don't think there's a very good understanding at department level about what is available at a college level, and improving those links is key. (Eric - teaching fellow)

Sessions included speakers from teams across the university involved in public engagement, including those developing the Festival and Lates programmes, Community Engagement, Schools Outreach and Patient Involvement. Day 2 of the Academy had a particular focus on this. Participants felt inspired by the value placed on engagement at a university level: 'I think the support for it [public engagement], the number of people who do it, the community drive for it [stands out]' (Terry - early career researcher). After Day 2, one participant wrote: 'At today's session I learnt that there are people available to help - use them!' This was echoed by discussions during the final day: 'Now I feel I know how to get support, I feel better integrated, but how do others find this?'

Participants spoke about this increased awareness of central support and opportunities in their follow-up interviews:

Because now when I receive the emails or check the newsletters or check the website, I am always curious to see what is going on, and if I have any chance to participate in that ... And trying to apply for anything that is relevant to me and would fit nicely inside my schedule. (Maria - early career researcher)

The revelation for our team was that this awareness was new and was a result of the Academy. Participants had technically had access to the information before, but they had lacked either confidence or know-how to make use of it, and the opportunity to meet the right people and ask questions at the Academy changed this.

\section{Career and time pressure}

A continued barrier faced by participants that we had perhaps anticipated was achieving a balance between engagement work and their everyday role. Structural barriers, such as time limitations, along with confidence and skills development, are known to be central to willingness and ability to do public engagement (Poliakoff and Webb, 2007; Hamlyn et al., 2015).

Five participants mentioned that the course provided an important protected time to focus on engagement:

I think having the opportunity to spend that time, those sessions where you specifically think about that. You are carving out a portion of time that you wouldn't normally do. I think that's been particularly useful. (Christina professional services senior manager) 
One interviewee felt that the dedicated time was fundamental to finding space among competing pressures:

It provided me with a lot of momentum, I wouldn't have been able to do a stall without it. Getting such a complete idea. So really taking it from where I was, doing bits and pieces, to doing one complete thing myself. I know I can do that, I can do it again, and I would feel completely comfortable doing that. (Terry - early career researcher)

However, even by the end of the programme, two participants still described engagement as an additional, 'extra-curricular', aspect of their role, rather than as something embedded in their work (Jenny, Maria). Another spoke of trying to make it a more explicit part of their role in future:

I'm negotiating changing my role slightly, so that someone can take on more of the basic student admin, which will allow me to concentrate more on things like engagement, centre publicity, things like that. I'm really hoping that if this happens ... I might get some central events happening. (Hannah - professional services manager)

Difficulties with balancing engagement within job roles was mentioned most frequently by those who identified as researchers. These participants spoke of a need to maintain focus on the research, even at the expense of the engagement for the time being, to refocus and ensure that the research was 'keeping up' after having had some time to focus on engagement. They spoke of a struggle to keep both aspects of their roles going well:

I have also realized that if you want to do good outreach, you have to dedicate a lot of time, so it comes to a situation in which you might not have enough time if you want to be good at research and other aspects of your career. (Olivia - early career researcher)

And if I can achieve the pinnacles of science and get a fellowship, with the Wellcome Trust or something like that, then I can write the engagement in. So, if I can achieve at one, I can achieve the other. But it's going to have to be more on the science side for a while ... I think the issue with the research is that sometimes there are very intense periods, and sometimes there are times where you can take your foot off the pedal. Everything sort of worked out with the timing of the course, because l'd just got a paper in at the end of last year. And then it was starting things up again. And now we are in the phase of a large number of experiments, lots of collaborations going on. So I'm getting pulled in lots of different directions, and it's not necessarily easy at the moment to reappraise the engagement. And to do the engagement, I need the science job. (Terry - early career researcher)

Although we had anticipated the time and career pressure, it was revealing to see how our participants found space to manage it - through a 'when the time is right' approach, and through developing sometimes ambitious projects that they were passionate about, rather than just 'little and often'. It may be that there are times for 'silence' for researchers as well as times for communicating, even for those researchers who see engagement activity as fulfilling and as key to their role (Mellor and Webster, 2017).

Success seemed less clearly defined in engagement compared to core roles. One participant reflected on understanding what is expected within their usual research 
role, but felt less clear as to the measures of success in engagement, despite feeling that engagement activities are more impactful in a broader societal sense:

I'll always go back to the safety net of doing the research. In terms of, I know exactly what is expected of me, I know broadly speaking how to achieve it, I know that it will be tangible goals and if I achieve those then my career proceeds ... I've never actually done a qualification in engagement per se, I don't really know what would be expected of me in an engagement role. (Terry - early career researcher)

These reflections echo findings from other work with academics reporting that 'where PE was (individually) prioritized, it was hazardous if not deleterious to academic career progression', due to competing time pressures and potential stigma from peers (Watermeyer, 2015: 336; Burchell et al., 2009).

\section{Diversity in roles}

One of the most important learnings - and the one that prompted most change in the design of our teaching in the second year - was about the diversity of roles within research departments, and team members' resultant very different levels and areas of agency.

Even by the end of the Academy, three participants (all professional services staff) spoke of the limitations of their own roles in terms of some aspects of engagement. Specifically, they had concerns remaining about not knowing the subject well enough to develop engagement ideas: We don't actively do the research, so it makes it more difficult to get together the actual ideas and things like that' (Jenny - technician).

If they [PhD students] come up with an idea, then it's easier for me to support them. If they don't come up with an idea, then it's a bit harder for me. I can put them together as a group and try to get them to come up with an idea. But I won't be in a position to come up with the idea myself. (Sabina - professional services manager)

In contrast, another non-researcher spoke about how she saw this position as a strength, and how it helped her to be a bridge between the research and public audiences:

I'm a history and politics student, I'm not a scientist. At all. But over the last nearly twenty years, I've been working in fields that are vastly different to mine. I can speak about [a topic] in a layman's view, and I see how exciting it is. And I wouldn't know about all of this if I wasn't working in the department and seeing it. Being able to be in a role where I can bring that out, and actually be in a role where I can bring it for the public to see it and engage with it, in what we are doing. It's amazing! (Christina - professional services senior manager)

While engagement professionals have expertise in engagement, they often do not have expertise in the research areas of the departments in which they work. This last comment gives a value to not being an expert in the content - to be able to provide a fresh perspective more aligned to that of potential public audiences. But in a research department, not being an expert can also be uncomfortable and feel like a limitation, as noted in the first two comments. Engagement practitioners in (usually central) engagement roles have skills, identity and departmental context all aligned in support of their role. It was an important learning for us that those in non-research roles within research departments had questions of role and identity to wrestle with 
when developing their engagement skills. In the first year of Academy teaching, we made the lives of participants with this sort of background more difficult by assuming that everyone in a research department was an expert in that subject - changing this for the second year was an important step.

\section{Understanding each other: How far could we connect research and engagement cultures?}

\section{Confidence, knowledge and skills in engagement}

All interviewees participating in the Academy reported an increase in their own confidence and knowledge about engagement. An increase in confidence seemed particularly important for those working in professional services roles (as opposed to researchers) who, as discussed above, were 'one step removed' from the topic:

It has definitely made me more enthusiastic about it [public engagement], and more confident about being able to get involved in things. I liked the idea of it in the first place, but it has given me more of an insight and more confidence. (Hannah - professional services manager)

Confidence and increased sense of capability influence individuals' willingness or intentions to engage, along with other factors, such as attitudes to engagement, whether they feel engagement will have a positive impact and feeling that they have the time to engage (Besley et al., 2018; Poliakoff and Webb, 2007).

An increase in confidence - something experienced by all participants - was linked to an increase in awareness and knowledge. Six interviewees developed understanding of the process of developing effective engagement projects and the importance of considering aims and audiences. For example:

I mean the one thing that really did strike me was understanding your audience and understanding your objectives. And I think possibly before, I thought more about the medium rather than the actual objective. It needs to be objective focused. So it's all very well having an event at the front hall, but if you are focusing on kids, you need to know why they are going to be there, why might they turn up, what is the outcome going to be for them. (Eric - teaching fellow)

I suppose it made me more aware of how to make it effective. Not just, say, fun. But how to make it so that your audience actually takes something away from the experience, as well as just having a nice time. (Jenny - technician)

Participants also demonstrated a broader understanding of what engagement was and why it was important, from a narrower starting point:

I guess the Academy helped me to understand it [public engagement] more. Whereas before, all I had heard was the term 'outreach'. I knew it had something to do with, I think it was more centred around, 'here is research we do and we want to show it off'. Whereas the Academy kind of helped me to realize, actually the public has a right to know about this, it's not about the researchers, the public needs to engage with this ... Before, I thought of outreach as something you ticked. Whereas having been to the Academy, it just made me understand it more, and just the different opportunities that were out there. (Sabina - professional services manager) 
This is an important development, given that one of the cultural differences observed between research staff and engagement professionals is a difference in the definitions of public engagement (Besley and Tanner, 2011; Grand et al., 2015).

Participants mentioned developing skills that supported their departmental work, for example around presentation and communication skills, as well as project management and creativity. Transferable communication skills, with applications to teaching and interactions with funders, have been evidenced as among key benefits of other training and schools engagement programmes (Cerrato et al., 2018; Stylinski et al., 2018):

So, it helps me to think about the big picture. This is crucial, even if you want to write a paper, sometimes you forget about the big picture. So, if I have somebody else from [department] who has no idea what I am doing. It helps me to stand back from being so detailed, and help me to tell a story, a broad story. For public engagement, I need to take two, three steps back, but those are important steps. And it helps me when I need to explain to my friends or my parents what I am doing. I cannot explain to my mum the work that I am doing, but I can explain the difference that I am making. Again, public engagement helped me. (Maria - early career researcher)

Some aspects of engagement required more 'work' - they were more difficult to incorporate, understand and make time for. One such area was evaluation and reflective practice. Five participants talked about an increase in their understanding of evaluation and how to assess the success of their engagement, whereas most had struggled to put this into practice:

I suppose I feel as though I have more knowledge, and more information about how to pitch things, and different audiences to pitch things to. And how to get feedback, even if I don't do it! (Hannah - professional services manager)

This brought to our attention the amount of time and skill required to do evaluation; this area of engagement work was harder to master than other aspects. Evaluation may be a key specialism of public engagement practitioners, and it perhaps requires longer-term support rather than training alone. This finding mirrors results from institutional surveys suggesting that while participation in engagement activities may be more widespread, evaluation of engagement among researchers is rare (Grand et al., 2015).

\section{Language and positioning: Reflecting on science in society}

Although participants developed skills, understanding and confidence in many aspects, one area of cultural disconnect that caused some difficulty was when reflecting on social science research. Participants struggled with the language used, for example, the use of the term 'symbolic violence' in one paper, which the participants found to be quite confronting. Some were wary of the methods used, in particular suggesting that the qualitative study they had read presented a 'case study', but that they were sceptical about fully embracing the findings. The critical tone of one paper, and its broad use of the term 'scientist' to refer to those working within a scientific field, the participants found to be attacking, and they felt inclined to defend science as a sector. This gap between those researching (social scientists) and those practising public engagement (such as our participants) was found to be pervasive in Chilvers' (2013) 
study into the actors in public dialogue about science, and it is illustrated in the exchange in Salmon et al. (2017).

For both ourselves and Miller et al. (2009), the discursive sessions tended to be the most difficult to design and facilitate effectively, and at times participants did not immediately recognize a benefit in a tangible skill or new knowledge. Nevertheless, we found that sessions reflecting on the role of scientists or science in culture, when paired with the practical workshops to put the ideas into practice, were fundamental in supporting participants to become reflexive public engagement practitioners. It is our belief that while the gaps between the cultural spheres of social science research into public engagement, and those practising engagement, are vast and uncomfortable to navigate, this exposure to new ideas supported our participants in the broadening of their understanding and perspectives in engagement, such as an increased focus on the audience or value in reflection.

\section{Beliefs about engagement roles: Developing a sense of agency}

Studies show that researchers see engagement as part of their role and as part of their everyday practice (Burchell et al., 2009; Hamlyn et al., 2015). However, there is a difference between seeing engagement as a general responsibility of scientists and seeing it as a core part of your own identity. Participants described impacts relating to a developed awareness and sense of identity in their own roles as supporting this bridge between engagement work and other activities within the university (including research and teaching). Such a focus on identity is rare in terms of the goals of many public engagement training programmes (Silva and Bultitude, 2009):

So what I have taken from that, maybe slightly philosophical, is that you don't have to be an expert of the field to deliver outreach activity, you just need to be keen on doing it, and you need to know why you are doing that. So, my particular motivation is that to show that maths has all of these motivations, and I would like for everyone to be aware. And I think that this Academy reinforced this in me. (Abby - professional services manager)

Another participant had always felt comfortable in this bridging role, but felt that the Academy supported her agency in doing so:

I am kind of a translator between the scientists that wouldn't necessarily know the knowledge that they take for granted, and the way it gets explained to people who don't work in that environment in a day-byday basis ... One of the things that is really good about the programme is that it gives you the confidence to, you don't have to wait - you don't have to say, 'well I'm not in a public engagement role', you know 'I'm just an administrator or the academic, what do I know about organizing something'. But it gives you that confidence to say, 'oh, I could arrange something like this'. (Christina - professional services senior manager)

A researcher felt a similar increase in freedom and agency:

It gives me an opportunity to manage something that is my own thing. Without having any requirement to my PI [principal investigator] or the department. And feeling constricted that I can't say something because it's not my idea. So, it gives me that freedom that I don't necessarily have within my work. (Terry - early career researcher) 


\section{Supporting others within the culture of engagement}

Many of the Academy participants saw their role as not only delivering engagement themselves but also to support others in their public engagement. Through an understanding of the culture of engagement compared to other aspects of university culture, the participants could support others to navigate areas of disconnect, such as accessing support and developing ideas. Five participants spoke about their role in motivating others to do more engagement:

There was nothing happening before, and I used my expertise from the Engagement Academy and my contacts, just to bring some enthusiasm to the group about delivering this sort of activity. (Abby - professional services manager)

Other participants described their role as a facilitator, using what they had learnt from the Academy to offer guidance to other members of staff and PhD students in the development of their engagement ideas:

So I was able to take what I've learnt on the course and go through it with [colleagues]. And say, well, first off you need to be looking at - what do you want to achieve? And who is your audience, and what are your perspectives? And it was really good! To have that stuff in little bits helping out ... I've been meeting lots of people now, and I've always tried to get across this - you need to have an aim and objective. Why are you doing this, what are they going to get out of it, who is your target audience, what are you going to get out of it? (Eric - teaching fellow)

An increased confidence through the course has enabled some to grow aspirations for what their group might achieve: 'I want to target a variety of audiences, it's not only about kids from school'. (Abby - professional services manager)

\section{Further research}

This paper is based on the reflections of a group of individuals taking part in one training course within a single institution. Although the needs and motivations of the group appear to mirror trends within the literature, there are of course issues when generalizing findings to other contexts. In particular, Imperial College London is an institution focused on science, technology, engineering and medicine. A potential future study could explore whether such issues and impacts hold true across the different cultures within the arts and humanities. Similarly, although participants were from diverse roles and backgrounds, there were no senior academic staff within the group. It may be fruitful to explore whether the structural and cultural gaps identified would pose a challenge or opportunity in a similar way for senior members of academic staff, as research has indicated that there may be a relationship between the seniority of a researcher and their involvement in public engagement (Bauer and Jensen, 2011).

\section{Conclusion}

When I did the Imperial Festival, it made me realize that what I do is important ... The college as a whole, seeing all of the research that is done - it's affecting people's lives. And then you realize, it's not just admin 
that I do, it's supporting people to do the research, and getting people to connect to one another and network. (Sabina - professional services manager)

A university is a community - necessarily fragmented, but, as the comment above reflects, also united. The Academy brought various university staff together as a collective - to learn from one another, reflect on their individual positions and journeys, and form a network of individuals who are working across barriers and boundaries within the university to achieve engagement. Structural and cultural differences are not unique to public engagement - they exist in many aspects of higher education. However, this paper shows how they are particularly important influences within the context of public engagement, where individuals need to work in new and different ways - often outside their main roles, practices and networks, across disciplines and in new spaces with different skills. The Academy was (and remains, because we are repeating the programme) a big investment in time for participants - but we believe that the long programme, with its emphasis on discussion, reflection and community, is a distinctive and important way of supporting engagement in today's university context.

Those participating in engagement across the university are diverse in the positions they take within departments, and in how they are able to work across spaces and contexts to achieve engagement. In bringing this diverse group together, and in being part of these discussions, we learnt a great deal about the structural and cultural factors affecting engagement in our context.

The Engagement Academy provided a number of ways in which participants were supported to build and reflect on their engagement identity. The sessions enabled space to network and provide feedback on ideas, the course structure provided multiple touchpoints through which confidence grew, and the group (including the authors) learnt together. Extended, dedicated time facilitated networking, trust and reflection. It also allowed the participants to try out ideas, safe to fail, and develop skills in areas that they saw as distinct from their varied everyday roles. Practically, participants were able to better understand and access central and institutional support for engagement, as well as working out how to embed what they had learnt and to drive progress within their own more localized contexts.

Within a university and public engagement sector more broadly, there are several different cultures at play: research culture, the work of engagement practitioners, and social science research into public engagement and science communication are just three (Salmon et al., 2017). Through their experiences on the Academy, participants engaged in different cultural practices, in particular adopting the role, thinking and behaviours of an engagement practitioner. This practitioner role included being reflexive about their ideas, and creative in their approaches, and providing more freedom in their projects. Many went on to adopt an enabling role for other colleagues or students, sharing their learning, guidance and motivation.

What we saw in terms of bridging structural and cultural gaps was powerful, and it lasted beyond the immediate course. However, a struggle remained for participants in balancing engagement with their role, be that in research, teaching or administration, and, in particular, in prioritizing time for engagement among other responsibilities. A disconnect also remained in some more 'cultural' areas - including social science research and evaluation.

While remaining a barrier for progress in engagement, these areas of disconnect may actually represent diversity and strength in the area of public engagement - we need research and all of the roles and areas of work that facilitate it, teaching and education, for engagement to happen. Through the Engagement Academy, we see 
therefore that perhaps the challenge in increasing participation in public engagement cannot be solved with increases in skills, time or funds alone. What is required is a deeper level of understanding, appreciation and community building across these areas of cultural and structural disconnect. The Engagement Academy facilitated this by keeping community building, identity and reflection at its heart: we believe that the investment in time and effort was worthwhile.

\section{Notes on the contributors}

Amy Seakins works in the central Public Engagement Team at Imperial College London, supporting staff and students with their societal engagement. This involves training programmes such as the Engagement Academy, networks, seed funding, awards and evaluation support. Before Imperial, Amy was a social science researcher looking at public engagement and science capital.

Alexandra Fitzsimmons teaches museum studies on the MSc in Science Communication at Imperial College London, drawing on over a decade of experience working in the museum sector on exhibition design and learning experiences. In addition to this, she is a founder of a family learning charity that aims to make maths sociable, accessible and enjoyable. She is also a director of a science-arts theatre company.

\section{References}

Baram-Tsabari, A. and Lewenstein, B.V. (2017) 'Science communication training: What are we trying to teach?'. International Journal of Science Education, Part B: Communication and Public Engagement, 7 (3), 285-300. Online. https://doi.org/10.1080/21548455.2017.1303756

Bauer, M.W. and Jensen, P. (2011) 'The mobilization of scientists for public engagement'. Public Understanding of Science, 20 (1), 3-11. Online. https://doi.org/10.1177/0963662510394457

Besley, J.C., Dudo, A. and Storksdieck, M. (2015) 'Scientists' views about communication training'. Journal of Research in Science Teaching, 52 (2), 199-220. Online. https://doi.org/10.1002/ tea.21186

Besley, J.C., Dudo, A., Yuan, S. and Lawrence, F. (2018) 'Understanding scientists' willingness to engage'. Science Communication, 40 (5), 559-90. Online. https://doi.org/10.1177/1075547018786561

Besley, J.C. and Tanner, A.H. (2011) 'What science communication scholars think about training scientists to communicate'. Science Communication, 33 (2), 239-63. Online. https://doi.org/10.1177/1075547010386972

Burchell, K., Franklin, S. and Holden, K. (2009) Public Culture as Professional Science: Final report of the ScoPE project (Scientists on public engagement: From communication to deliberation?). London: London School of Economics and Political Science. Online. https://eprints.kingston. ac.uk/20016/ (accessed 3 May 2019).

Burchell, K., Sheppard, C. and Chambers, J. (2017) 'A "work in progress"? UK researchers and participation in public engagement'. Research for All, 1 (1), 198-224. Online. https://doi.org/10.18546/RFA.01.1.16

Cerrato, S., Daelli, V., Pertot, H. and Puccioni, O. (2018) 'The public-engaged scientists: Motivations, enablers and barriers'. Research for All, 2 (2), 313-22. Online. https://doi.org/10.18546/ RFA.02.2.09

Chilvers, J. (2013) 'Reflexive engagement? Actors, learning, and reflexivity in public dialogue on science and technology'. Science Communication, 35 (3), 283-310. Online. https://doi.org/10.1177/1075547012454598

Duncan, S. and Oliver, S. (2017) 'Editorial'. Research for All, 1 (1), 1-5. Online. https://doi.org/10.18546/RFA.01.1.01

Gibbs, G.R. (2007) Analyzing Qualitative Data. London: SAGE Publications.

Glaser, B.G. and Strauss, A.L. (1967) The Discovery of Grounded Theory: Strategies for qualitative research. New York: Aldine de Gruyter.

Grand, A., Davies, G., Holliman, R. and Adams, A. (2015) 'Mapping public engagement with research in a UK university'. PLoS One, 10 (4), Article e0121874, 1-19. Online. https://doi.org/10.1371/journal.pone.0121874 
Hamlyn, B., Shanahan, M., Lewis, H., O’Donoghue, E., Hanson, T. and Burchell, K. (2015) Factors Affecting Public Engagement by Researchers: A study on behalf of a consortium of UK public research funders. London: TNS BMRB and Policy Studies Institute. Online. https://wellcome.ac.uk/sites/default/files/wtp060033_0.pdf (accessed 3 May 2019).

Mellor, F. (2013) 'Twenty years of teaching science communication: A case study of Imperial College's Master's programme'. Public Understanding of Science, 22 (8), 916-26. Online. https://doi.org/10.1177/0963662513489386

Mellor, F. and Webster, S. (eds) (2017) The Silences of Science: Gaps and pauses in the communication of science. London: Routledge.

Miller, S., Fahy, D. and the ESConet Team (2009) 'Can science communication workshops train scientists for reflexive public engagement? The ESConet experience'. Science Communication, 31 (1), 116-26. Online. https://doi.org/10.1177/1075547009339048

NCCPE (National Co-ordinating Centre for Public Engagement) (n.d.) The Beacons for Public Engagement. Bristol: National Co-ordinating Centre for Public Engagement. Online. www.publicengagement.ac.uk/sites/default/files/publication/nccpe_bridging_the_gap_ brochure_0_0.pdf (accessed 3 May 2019).

NCCPE (National Co-ordinating Centre for Public Engagement) and RCUK (Research Councils UK) (2017) Pathways to Culture Change: Lessons from the Catalyst Seed Fund programme: Interim report. Bristol: National Co-ordinating Centre for Public Engagement. Online. www.publicengagement.ac.uk/sites/default/files/publication/pathways_to_culture_change_final. pdf (accessed 3 May 2019).

Owen, D., Featherstone, H. and Leslie, K. (2016) The State of Play: Public engagement with research in UK universities. Swindon: Research Councils UK and Wellcome Trust. Online. www.publicengagement.ac.uk/sites/default/files/publication/state_of_play_final.pdf (accessed 3 May 2019).

Poliakoff, E. and Webb, T.L. (2007) 'What factors predict scientists' intentions to participate in public engagement of science activities?'. Science Communication, 29 (2), 242-63. Online. https://doi.org/10.1177/1075547007308009

Salmon, R.A., Priestley, R.K. and Goven, J. (2017) 'The reflexive scientist: An approach to transforming public engagement'. Journal of Environmental Studies and Sciences, 7, 53-68. Online. https://doi.org/10.1007/s13412-015-0274-4

Savin-Baden, M. and Howell Major, C. (2013) Qualitative Research: The essential guide to theory and practice. London: Routledge.

Schon, D.A. (1983) The Reflective Practitioner: How professionals think in action. New York: Basic Books.

Silva, J. and Bultitude, K. (2009) 'Best practice in communications training for public engagement with science, technology, engineering and mathematics'. Journal of Science Communication, 8 (2), 1-13. Online. https://doi.org/10.22323/2.08020203

Stylinski, C., Storksdieck, M., Canzoneri, N., Klein, E. and Johnson, A. (2018) 'Impacts of a comprehensive public engagement training and support program on scientists' outreach attitudes and practices'. International Journal of Science Education, Part B: Communication and Public Engagement, 8 (4), 340-54. Online. https://doi.org/10.1080/21548455.2018.1506188

Watermeyer, R. (2015) 'Lost in the "third space": The impact of public engagement in higher education on academic identity, research practice and career progression'. European Journal of Higher Education, 5 (3), 331-47. Online. https://doi.org/10.1080/21568235.2015.1044546

Wenger, E. (1998) Communities of Practice: Learning, meaning, and identity. Cambridge: Cambridge University Press. 